\title{
The New Asset Management: Implications of Servitization in Circular Economy
}

\author{
Unai Martínez de Estarrona ${ }^{1}$, Dammika Seneviratne ${ }^{2}$, \\ Roberto Villarejo ${ }^{3}$, and Diego Galar ${ }^{4}$ \\ ${ }^{1}$ TECNALIA Research and Innovation, Vitoria, Spain \\ ${ }^{2,3,4}$ TECNALIA Research and Innovation, Zaragoza, Spain \\ ${ }^{4}$ Division of Operation and Maintenance Engineering, Luleå University \\ of Technology, Luleå, Sweden \\ E-mail: unai.martinezdeestarrona@tecnalia.com; \\ dammika.seneviratne@tecnalia.com; roberto.villarejo@tecnalia.com; \\ diego.galar@tecnalia.com
}

Received 10 July 2018; Accepted 05 February 2019;

Publication 03 April 2019

\begin{abstract}
The circular economy, or reduce, reuse, recycle, is gaining ground and is supported by many governments, with consequences for businesses. In asset management, the change in the economy paradigm must be driven by a new formula focusing on asset resilience, productivity rates, and asset integrity, while minimizing waste. In the circular economy, spares and broken components acquire an importance not considered in linear economies where disposal was common. The circular economy uses technologies such as IoT and understands the whole supply chain as connected. This implies information sharing that is not typical of production environments, and it offers new opportunities, such as: joint maintenance optimization of supply chain actors, maintenance as a service for all actors, and increased supply chain efficiency. In a circular economy, maintenance providers must consider environmental compatibility, energy efficiency, and human health and safety.
\end{abstract}

Keywords: Circular economy, Asset management, Servitization.

Journal of Industrial Engineering and Management Science, Vol. 1, 109-120. doi: 10.13052/jiems2446-1822.2018.006

This is an Open Access publication. (c) 2019 the Author(s). All rights reserved. 


\section{Introduction}

Asset manufacturers are faced with two major changes affecting their business: servitization and the circular economy. Servitization is the latest trend in business models; in servitization, manufacturing companies retain ownership of assets throughout their lifetime. Companies adapting these business models at an early stage have experienced a growth of 5 to 10 percent [1]. One wellrecognized servitization model is pay-per-copy printers; other businesses have developed similar solutions, including for washing machines, clothing rental services, car sharing, and high-performance computing.

The introduction of servitized business models where the use or the function of a product is sold instead of the product itself, has been acknowledged as one possible enabling factor of the circular economy arena into companies [2-4]. For instance, in the transportation sector, vehicle sharing offerings where the providers do not sell cars but offer solutions such as rental or lease through a servitized schemes [5]. This has been wildly used example in showing the application of circular economy principles in many literature $[5,6]$.

Servitization takes advantage of the digitalization of assets. Product digitalization offers valuable information and permits supervision over the lifecycle. Internet of Things (IoT) is the enabler of digitalization. IoT-related companies have grown in both number and size. According to Forbes, this growth shows, on average, a 23\% CAGR (Compound Annual Growth Rate), which, in monetary terms, implies a growth from $\$ 157 \mathrm{~B}$ in 2016 to an anticipated \$457B in 2020. A more detailed analysis by GrowthEnabler [2] shows that Smart Cities have cornered $26 \%$ of the IoT market. Industrial IoT represents $24 \%$, connected health $20 \%$, and smart homes $14 \%$; the rest of the markets are less significant (see Figure 1). At this point, IoT-related technologies are a commodity and are affordable for most companies.

The new digital technologies form the backbone of the fourth industrial revolution. For instance, IoT, 3D printing, Big Data and related analytics, virtual and augmented reality, has been indicated as "disruptive" by Gatner. Furthermore, the disruptive technologies are rapidly changing the offerings and presenting the existing service providing companies [8]. This enables the companies to percent new servitization business models and also to change their existing servitization business models towards the circular economic principles [8-12]. A practical example is the "Power-by-the-Hour" program provided by Rolls-Royce [13]. The contribution of the new digital technologies for the transition of old business models toward the curricular economics principles has not been properly analyzed yet [5]. 


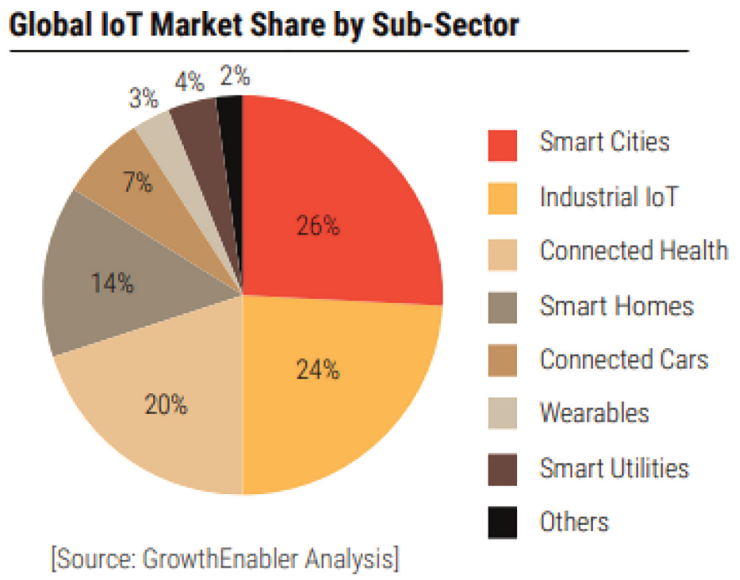

Figure 1 Global IoT market share.

The second major change affecting asset manufacturers is the popularity of the circular economy, defined as efficient resource management, increased recycling, and reduced waste [1], more commonly seen under the popular rubric: reduce, reuse, recycle.

This paper describes the main circular economic principles and then discusses the asset management implications considering the servitization within the circular economy. Furthermore, the manuscript highlights the implications of servitization in the manufacturing industries.

\section{Circular Economy}

The circular economy considers the "integration of economic activity and environmental wellbeing in a sustainable way" [14]. It is not a new concept; it was introduced in 1989 by Pearce and Turner, following studies on the ecological economy. In recent years, many governments have introduced circular economy principles and are promoting research on the topic. For example, the Danish government is working on the transformation to a circular economy as one of the pillars for the development of the country and its industry. The Netherlands and Italy signed manifestos in 2017; Finland defined a circular economy roadmap in 2016; Spain and the United Kingdom are working on the development of policies. But the example to follow seems to be China. The Chinese government defined its circular economy strategy in 2006 and enacted laws in 2008. 


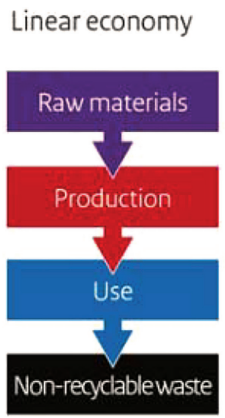

Reuse economy

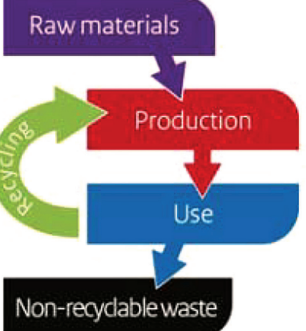

Circular economy

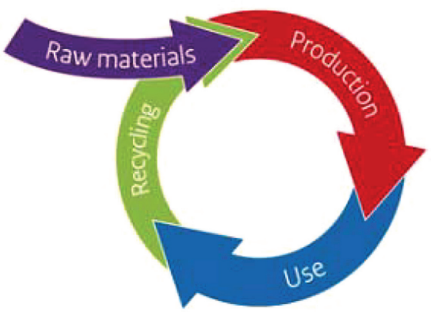

Figure 2 From linear to circular economy.

Research and the identification of best practices show that a transition to the circular economy can produce a more innovative, resilient, and productive economy. The following advantages are particular salient:

Substantial saving of net material. In the first two reports of the Ellen MacArthur Foundation [15], a detailed model at the product level is used to estimate the value of an "advanced" circular economy scenario. Taking into account only the sectors of complex goods of medium duration (for example, consumer electronics), the model finds estimated savings of up to 630,000 million US dollars per year in Europe after 2020. For fast-moving consumer goods (for example, food and drinks, clothes and packaging), the economic opportunity is estimated at more than 700,000 million US dollars a year worldwide, or material savings of approximately $20 \%$.

Reduction of exposure to price volatility. A natural consequence of net material savings would be a downward shift in the cost curve of raw materials. In the case of steel, global net material savings could add up to more than 100 million tons of iron ore by 2025 if applied to a considerable part of the material flow (i.e. in the intensive steel sectors of the automotive industry and other transport sectors, which account for $40 \%$ of the demand). Furthermore, this shift would move the steel industry from the right side of the curve of costs of raw materials (increase), and this would probably reduce the volatility driven by demand increases.

Greater economic development. The study "Growth Within: A Circular Economy Vision for a Competitive Europe" [16] estimates that a change to the circular economy in three basic industrial sectors (mobility, food, environment) would allow Europe to increase productivity of resources by up to $3 \%$ per year. In addition, it would generate 1.2 trillion euros in benefits 
from non-resources and raise the total annual benefits for Europe to around 1.8 trillion euros. On a global scale, multiple studies have consistently shown the positive impacts of the circular economy using different methodologies and across sectors and geographies: they show a GDP growth of $0.8-7.0 \%$, the creation of $0.2-3 \%$ more new jobs, and a $48 \%$ reduction of carbon emissions by 2030 .

Greater potential for innovation and job creation. Circularity has proven to be powerful; it can generate creative solutions and stimulate innovation. An academic meta-study carried out for the "Growth Within" report finds a positive effect on employment when the circular economy is implemented.

Increased resilience in living systems and in the economy. Land degradation costs around 40 billion US dollars a year worldwide, without taking into account the hidden costs of increased fertilizer use, the loss of biodiversity, and the loss of unique landscapes. The application of the principles of circular economy, which promote greater productivity of the land, less waste in the food value chain, and the return of nutrients to the soil, will increase the value of land and soil as assets.

As mentioned, governments across the globe have considered or are considering a circular economy to prevent the waste of resources. However, as explained in the following section, the shift to servitization is forcing the producers of assets to be asset owners and to sell services instead of assets. This shift is complicated by the move to the circular economy.

\section{Asset Management Implications}

As noted above, we are seeing a shift towards servitization. At the same time, governments and society are trying to persuade companies to achieve a more sustainable environment through circular economy policies.

Servitization is a challenge for industrial companies who are unaccustomed to designing services and who have traditionally relied on sales for their revenue. With servitization, assets are owned and maintained by asset manufacturers during the product's lifecycle. This change must be accommodated by companies if they wish to remain competitive.

It would seem that accommodating this shift, as well as the move to a circular economy, might be difficult for asset manufacturers, but in fact, many principles of the circular economy are aligned with servitization in many areas. The following sections discuss circular economy principles and show their benefits for asset manufacturing and managing companies. Note that 
we do not consider all principles of the circular economy; some, such as energy production from renewable sources, have no direct application to the asset industry.

Reduce is a basic principle of sustainable manufacturing and the circular economy. Reduced material and energy consumption ensure more profitable assets, as well as long lasting assets that will be profitable for a longer period of time. If assets need to last longer, consume less power, and be built using fewer materials, maintenance policies are crucial. Connected devices play a key role; they are the facilitators of data collection and asset management, and, as such, they enable the use of new maintenance techniques.

Reuse is an important principle for parts. Proper application of this principle will lead to reduced manufacturing needs, as used machines or subsystems are reused after a first life-cycle. When reusing parts, a key aspect is determining their reliability and remaining useful life.

In recover, a concept very similar to reuse, assets are collected at the end of a lifecycle. Their parts are disassembled, sorted and cleaned for use in subsequent lifecycles [17].

Systems must be redesigned to be more efficient in material and energy use requirements. The redesign must also focus on reusing and recovering materials and subsystems from previous assets. The circular economy drives redesign. A better understanding of an asset's environment and working conditions can generate design feedback that can be integrated within a company's design process and create more efficient assets in the future.

Remanufacture refers to the reprocessing of worn assets in order to bring them back to their original state, reusing and recovering as many parts as possible. This particular principle of the circular economy includes most of the requirements of the preceding circular economy principles. Note that when an asset is remanufactured, and recovered parts are used to restore it, it is necessary to define how worn it is, i.e., to determine the remaining useful life of the whole asset.

In the ISO 55000 definition, asset management is the "coordinated activity of an organisation to realize value from assets". This definition involves activities in different fields, including identifying what assets are needed, setting funding requirements, acquiring assets, providing maintenance, and disposing of or renewing assets [18]. While this asset management vision is asset-user oriented, it can be applied to asset manufacturers as they adapt to the circular economy and servitization. 
First, as service providers, asset manufacturers need to be aware of the total cost of ownership of their assets. In traditional cost structures, the cost of maintenance and repairs was the customer's concern, but service oriented businesses may face penalties if asset availability is not met. Therefore, the total cost of ownership should consider the risk of breakdowns and their influence on customers' business. This is a key point for service providers; all maintenance costs are supposed to be borne by providers. Thus, their risk management should consider issues and scenarios that would not otherwise be crucial to them. Asset availability is directly related to maintenance and design. If the asset is designed to have a long-life expectancy, revenues are likely to be higher because there will be less need for maintenance and there may be a possibility of reusing reliable subsystems from old machines in new ones, or using the worn asset in a less demanding environment after a small retrofit.

Second, asset integrity needs to be guaranteed to ensure the availability of contracted machines in pay-per-use contracts. But applying the principles of the circular economy (reducing, reusing, and remanufacturing assets or parts of them) is risky when asset reliability is crucial for business outcomes. Therefore, remaining useful life calculations need to be precise to avoid machine breakdown and avoid penalties from users. Developing precise calculations is the basis for the optimization of maintenance actions. Even if some preventive maintenance actions will still be needed, these can be performed by asset users. Asset manufactures can center on offering predictive maintenance services which are perceived as value-added actions instead of costs. If predictive maintenance is a value-added service that customers are willing to pay for, achieving a prognostic system can be the key to achieving large incomes for asset manufacturers.

For purposes of prognosis, a current trend is to build digital twins for assets or their crucial parts. Digital twins can be personalised, taking into consideration specific conditions of a deployed asset, especially asset context and working requirements and conditions. Asset manufacturers should bear in mind that they are owners and managers of a fleet of machines that are exposed to diverse requirements in terms of working and environmental conditions. This presents an opportunity to gather valuable information about asset performance in a range of settings that would be impossible in a traditional business model.

Being aware of the context of operation of delivered assets and those that will be deployed in the future offers asset manufacturers/managers the following opportunities: 
- In a market defined by servitization, context awareness, together with prognostic systems or digital twins, offer the possibility of creating new services that will create added value. As an example, machine parameters can be changed or personalized to achieve higher production rates or preserve a machine from breakdown.

- When achieving the circular economy principles of reuse and remanufacture, a good definition of the future working environment of the asset is crucial. Considering both past and future conditions, the most suitable asset could be defined in order to build an asset that meets those requirements. This may mean building a completely new asset.

Finally, companies should include asset management in their strategies. New business models that focus on fulfilling customer needs through servitization need to develop asset management strategies as part of a successful business model. Assets are the vehicle through which companies will deliver services, and their management cannot be avoided. One of the most important considerations is that the longer an asset can fulfil its mission, the higher its revenue will be until the point when the cost of maintaining that asset increases exponentially, leaving no room for earnings.

\section{Conclusions}

Asset providers are turning to a new business model for two reasons. First, servitization is becoming a common practice whereby customers pay for machine availability and reliability instead of buying assets. Second, governments and society are pushing for a circular economy in which manufacturing is environmentally sustainable. These two changes present opportunities for fast moving companies, but they also present problems that need to be solved if companies are to make a profit.

One of the biggest challenges is how to manage assets that are deployed in customer facilities. In a nutshell, asset management needs to take into consideration the total cost of the ownership of assets. It needs to determine with precision and confidence the remaining useful life of machines and their subsystems in order to reuse or rebuild them. Maintenance pays an important role, as it will make the difference between a profitable business and a non-profitable one. Prognostic systems and digital twins are the key to success, while context awareness is crucial for the redesign process. All these factors and challenges need to be considered to create a basic asset 
management system capable of dealing with servitization requirements and a circular economy. Fortunately, enabling technologies such as IoT are popular and accessible for most industries.

\section{Acknowledgments}

This work was partially supported by the VIRTUAL (Development of virtual models for the improvement of the life of components and equipment goods) project funded by Basque Government and Smart-PdM (Intelligent approach for maintenance based on cyber physical systems) project. Without their support, this work would not have been possible.

\section{References}

[1] L. Probs, L. Frideres and B. Cambier, "Servitisation pay-per-use", Business Innovation Observatory, European Commission, 2016.

[2] Ellen MacArthur Foundation. Towards a Circular Economy, Economic and Business Rationale for an Accelerated Transition; Ellen MacArthur Foundation: Cowes, UK, 2012.

[3] G. C. Nobre and E. Tavares, Scientific literature analysis on big data and Internet of Things applications on circular economy: A bibliometric study. Scientometrics, Vol. 111, pp. 463-492, 2017.

[4] M. Lewandowski, Designing the Business Models for Circular Economy-Towards the Conceptual Framework. Sustainability, Vol. 8, pp. 43, 2016.

[5] B. Cohen and J. Kietzmann, Ride On! Mobility Business Models for the Sharing Economy. Organ. Environ., Vol. 27, pp. 279-296, 2014.

[6] Ellen MacArthur Foundation. Growth within: A Circular Economy Vision for a Competitive Europe; Ellen MacArthur Foundation: Cowes, UK, 2015.

[7] GrowthEnabler, Market pulse report, Internet of Things (IoT). GrowthEnabler, 2017.

[8] B. Kamp and G. Parry, Servitization and advanced business services as levers for competitiveness. Ind. Mark. Manag., Vol. 60, pp. 11-16, 2017.

[9] T. Baines and H. W. Lightfoot, Servitization of the manufacturing firm. Exploring the operations practices and technologies that deliver advanced services. Int. J. Oper. Prod. Manag., Vol. 34, pp. 2-35, 2013. 
[10] S. Lenka, V. Parida, and J. Wincent, Digitalization Capabilities as Enablers of Value Co-Creation in Servitizing Firms. Psychol. Mark., Vol. 34, pp 92-100, 2017.

[11] M. Despeisse, M. Baumers, P. Brown, F. Charnley, S. J. Ford, A. Garmulewicz, S. Knowles, T. H. W. Minshall, L. Mortara, F. P. Reed-Tsochas, et al. Unlocking value for a circular economy through 3D printing: A research agenda. Technol. Forecast. Soc. Chang., Vol. 115, pp. 75-84, 2017.

[12] V. Parida, D. R. Sjödin, J. Wincent, and M. Kohtamäki, Mastering the transition to product-service provision: Insights into business models, Learning activities, and capabilities. Res. Technol. Manag. Vol. 57, pp. 44-52, 2014.

[13] G. Bressanelli, F. Adrodegari, M. Perona, and N. Saccani. "Exploring how usage-focused business models enable circular economy through digital technologies." Sustainability, Vol. 10, no. 3, 2018.

[14] A. Murray, K. Skene, and K. Haynes, "The Circular Economy: An Interdisciplinary Exploration of the Concept and Application in a Global Context" J. Bus. Ethics, 140, pp. 369-380, 2017.

[15] E. Macarthur, "Towards the circular economy", Ellen Macarthur Fundation, 2014.

[16] E. Macarthur, K. Zumwinkel and M. R. Stuchtey, "Growth within: a circular economy for a competitive Europe", McKinsey Center for Business and Environment, 2015.

[17] I. S. Jawahir, and R. Bradley, "Technological Elements of Circular Economy and the Principles of 6R-Based Closed-loop Material Flow in Sustainable Manufacturing", Procedia CIRP, Vol. 40, pp. 103-108, 2016.

[18] N. A. J. Hastings, "Physical Asset Management with an Introduction to ISO55000”, Springer International Publishing Switzerland, 2010. 


\section{Biographies}

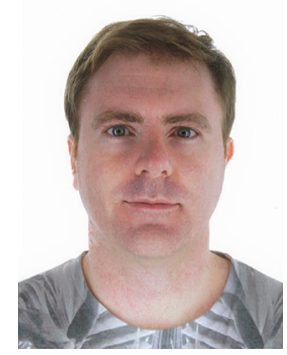

Unai Martínez de Estarrona is a Researcher in Maintenance and Reliability engineering. He attended the University of York where he received his MA in Management in 2015. He holds senior positions at Tecnalia Research and Innovation in the field of maintenance and reliability engineering. His research interests include asset management, condition monitoring and operation and maintenance engineering.

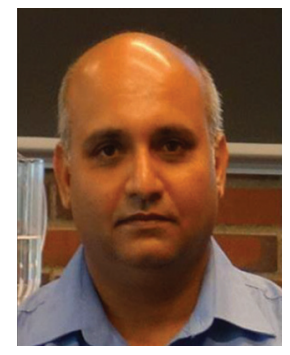

Dammika Seneviratne is a Researcher in Maintenance and Reliability engineering. He received his M.Sc. in Mechatronics Engineering from the Asian Institute of Technology, Thailand and $\mathrm{PhD}$ in Offshore Technology from the University of Stavanger. He was a Post-doctoral researcher in the Division of Operation and Maintenance, Luleå University of Technology, Luleå, Sweden. His research interests include condition monitoring, operation and maintenance engineering in engineering systems; risk based inspection planning in offshore oil and gas facilities; reliability and risk analysis and management, and risk based maintenance. 


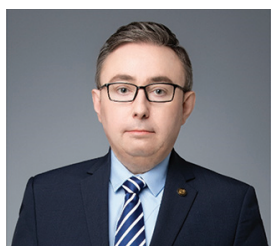

Diego Galar is Professor of Condition Monitoring in the Division of Operation and Maintenance Engineering at LTU, Luleå University of Technology where he is coordinating several $\mathrm{H} 2020$ projects related to different aspects of cyber physical systems, Industry 4.0, IoT or industrial Big Data. He was also involved in the SKF UTC centre located in Luleå focused on SMART bearings and also actively involved in national projects with the Swedish industry or funded by Swedish national agencies like Vinnova. He has been involved in the raw materials business of Scandinavia, especially with mining and oil and gas for Sweden and Norway respectively. Indeed, LKAB, Boliden or STATOIL have been partners or funders of projects in the CBM field for specific equipment like loaders, dumpers, rotating equipment, linear assets etc...

$\mathrm{He}$ is also principal researcher in Tecnalia (Spain), heading the Maintenance and Reliability research group within the Division of Industry and Transport.

He has authored more than five hundred journal and conference papers, books and technical reports in the field of maintenance, working also as member of editorial boards, scientific committees and chairing international journals and conferences and actively participating in national and international committees for standardization and R\&D in the topics of reliability and maintenance.

In the international arena, he has been visiting Professor in the Polytechnic of Braganza (Portugal), University of Valencia and NIU (USA) and the Universidad Pontificia Católica de Chile. Currently, he is visiting professor in University of Sunderland (UK), University of Maryland (USA), University of Stavanger (NOR) and Chongqing University in China. 